\title{
Effectiveness of an Infiltrant on sealing of Composite Restoration Margins with/without Artificial Caries
}

\author{
${ }^{1}$ Ozlem Tulunoglu, ${ }^{2} \mathrm{lbrahim}$ Fevzi Tulunoglu, ${ }^{3}$ Sibel A Antonson, ${ }^{4}$ Marc Campillo-Funollet \\ ${ }^{5}$ Donald Antonson, ${ }^{6}$ Carlos Munoz-Viveros
}

\begin{abstract}
Aim: The aim of this in vitro study was to evaluate the effectiveness of a resin infiltrant (ICON) on marginal sealing ability of class II resin restorations with/without-caries.
\end{abstract}

Materials and methods: Forty-eight noncarious human premolar teeth were embedded and $\mathrm{MO}$ and DO preparations of standard dimensions were prepared. The left side of dentin margins of the cavities were left nonbonded (UB) while the right side were bonded using total etch-bonding agent and all restored with a Nanohybrid composite. The teeth were thermocycled and half of the specimens in the UB and B groups were subjected to an artificial caries process. ICON was applied to caries and noncaries subgroups following the manufacturer's directions. Impressions were made at each step: after the restorations were completed, thermocycling, artificial caries procedures, and infiltrant application and the silicone tag lengths were measured with a stereomicroscope. The specimens were immersed in $0.5 \%$ basic fuchsine at $37^{\circ}$ C for 24 hours, sectioned and microleakage was evaluated with a stereomicroscope. Selected samples and their replicas were assessed for marginal quality under a stereomicroscope and SEM. Statistical evaluation of the data were made using Kruskal-Wallis, Mann-Whitney U and Wilcoxon Sign Rank tests.

Results: While bonding application did not create a meaningful difference, the thermocycling and artificial caries significantly increased the gap length and microleakage $(p<0.05)$. ICON application was decreased the microleakage, created gap-free margins and closed the gaps which were previously occurred at the same cavities $(p<0.05)$.

Conclusion: A resin infiltrant (ICON) application decreased the microleakage, created gap-free margins and closed the gaps, which previously occurred at the same cavities.

\footnotetext{
${ }^{1}$ Clinical Instructor, ${ }^{2,3}$ Associate Professor

${ }^{4}$ Researcher, ${ }^{5,6}$ Professor

${ }^{1}$ Department of Pediatric Dentistry, Case Western Reserve University, School of Dental Medicine, Ohio, USA

${ }^{2}$ Department of Comprehensive Care, Case Western Reserve University School of Dental Medicine, Ohio, USA

${ }^{3-6}$ Department of Restorative Dentistry, School of Dental Medicine, University at Buffalo, State University of New York New York, USA

Corresponding Author: Ozlem Tulunoglu, Clinical Instructor Department of Pediatric Dentistry, Case Western Reserve University, School of Dental Medicine, Cleveland, Ohio, USA Phone: 2167445884, e-mail: otulunoglu@yahoo.com
}

Clinical significance: Approximal application of resin infiltrant may increase the success of the class II composite restorations also reduced the risk of needing more complex restoration therapy.

Keywords: Artificial caries, Class II restorations, Gap formation, Mikroleakage, Resin infiltration.

How to cite this article: Tulunoglu O, Tulunoglu IF, Antonson SA, Campillo-FunolletM, Antonson D, Munoz-Viveros C. Effectiveness of an Infiltrant on Sealing of Composite Restoration Margins with/without Artificial Caries. J Contemp Dent Pract 2014;15(6): 717-725.

\section{Source of support: Nil}

Conflict of interest: None

\section{INTRODUCTION}

During the past decade, sealing and infiltrating has become one of the important philosophies in dentistry. Treatment strategies have in general changed from operative treatments to noninvasive strategies. ${ }^{1-3}$

The prevalence of proximal caries is still very high in both primary and permanent dentition. ${ }^{1}$ Clinical studies have shown that resin infiltration and sealing are promising treatments for proximal caries, radiographically with a depth around the enamel dentin junction. ${ }^{1-4}$ This is in agreement with studies showing that caries is a slow progressing disease and that lesion progression before cavitation occurs may be arrested. ${ }^{5,6}$ Meyer-Lueckel and Paris ${ }^{7}$ have suggested some successful nonoperative treatment initiatives, such as 'sealing of proximal early lesions and inhibition of enamel caries lesions by infiltration with low viscosity light curing resin'. This approach was described as 'micro invasive dentistry' which is one step further to minimally invasive dentistry. Therefore, the concept of sealing occlusal surfaces of enamel lesions, has been transferred to smooth surfaces using surface sealants, infiltrants and patches. ${ }^{7,8}$

Today, sealants are mostly used therapeutically on indication, attempting to arrest active noncavitated lesions. ${ }^{9}$ While adhesive application or surface sealing acts as a diffusion barrier on the top of the lesion surface, the infiltration technique creates a barrier inside the lesion by replacing the mineral lost with a low-viscosity light-curing resin. ${ }^{10}$ 
Since, a $100 \%$ perfect margin is not realistically achievable for composite restorations on the enamel-cement connection, the application of low-viscosity low molecular weight, unfilled resins to previously placed esthetic restorations is currently accepted as a clinical sealing technique. Use of an adhesive patch especially designed to seal smooth enamel surfaces, is another approach that has been developed for this purpose. ${ }^{8,11}$ Additionally, other recently developed materials are nanotechnology liquid polishers. Their objective is to create a marginal seal with the ability to fill micro gaps and reduce micro leakage at composite margins. ${ }^{12}$

Previous studies ${ }^{8,11,13-16}$ on use of rebonding, surface sealants and adhesive patches showed promising result in terms of limiting or possibly eliminating the microleakage in proximal lesions. However, there are no studies on the effect of usage of resin infiltrants on the previously made composite resin restoration-enamel interface and on the same area with the initial stage secondary carious lesions in terms of microleakage and gap formation.

So, the aim of this study was to evaluate the effects of a resin infiltrant on microleakage and gap at the composite resin-enamel margin with and without artificial caries lesions. The null hypotheses tested were as follows:

- $H_{0} 1$ : Bonding application helps to reduce the gap formation. The gaps at the resin-enamel interface of composite restorations are not affected by thermocycling, artificial caries, resin infiltrant application or with any of their combinations.

- $\mathrm{H}_{0} 2$ : Bonding application helps reduce microleakage. The microleakage at the resin-enamel interface of composite restorations are not affected by thermocycling, artificial caries, resin infiltrant application or with any of their combinations.

\section{MATERIALS AND METHODS}

Forty eight fresh, sound, non-carious, unrestored human premolar teeth extracted for orthodontic reasons were stored in an aqueous solution of $0.5 \%$ chloramine $\mathrm{T}$ at $4^{\circ} \mathrm{C}$ for 30 days. The Institutional Review Board of University at Buffalo, School of Dental Medicine, approved the use of teeth. The selected teeth were debrided of residual plaque and calculus and examined under a light microscope at $20 \times$ to ensure that they were free of defects. The study protocol is briefly described in Flow Chart 1.

\section{Preparation of Test Samples}

Twenty-four rectangular shaped boxes were made from pink sheet wax with a separation connecting the long sides of the rectangle at their midpoints. To mimic the clinical situation and to standardize the restorative procedure the root portion of two premolar teeth were embedded into putty silicone placed into the rectangular shaped blocks, in tight contact at their proximal surfaces.

Standard mesioocclusal (MO) and distoocclusal(DO) cavities were prepared for each tooth $(2 \mathrm{~mm}$ wide buccolingually, $2 \mathrm{~mm}$ occlusally and axially above the enamelcement junction). Cavity preparations were made using a flat-end parallel cylindrical diamond bur (coarse \# 836 cutting length 6.0; head size 014, Brasseler USA) under simulated clinical conditions and water as an irrigant. The inner angles of the preparations were rounded and the margins were not beveled to simulate comparable previous studies. $^{17}$

The blocks with embedded teeth were randomly divided into two main groups. For each tooth, one proximal preparation was left nonbonded (UB) (n: 48 OM) while the cavity on the opposing proximal side was bonded using Optibond Solo Plus, (Kerr, CA, USA) (B) (n: 48 OD) (Fig. 1). All teeth were restored and polymerized with 2 $\mathrm{mm}$ increments using a nanohybrid composite (Tetric EvoCeram Vivadent, Ivoclar, AG Schaan, Liechtenstein) according to the manufacturer's directions (Table 1).

The dentin bonding and resin composite were light polymerized for 40 seconds on each increment using the WIP Junior Dental Curing Light (Bisco, Schaumburg, IL, USA). The intensity of the light was checked periodically with a hand-held dental radiometer (Model 100 Curing Radiometer, Demetron Research Corp., Danbury CT, USA). Prior to the finishing process, visible overhangs were removed using a posterior scaler (Hu-Friedy, Leimen, Germany). Proximal margins were finished with flexible disks (Sof-Lex Pop-on, 3M ESPE, St Paul, MN, USA). One operator performed all restorations and all measurements were performed blindly by two independent observers (Inter-examiner Cohen's K $=0.96$ ).

After storage in distilled water at $37^{\circ} \mathrm{C}$ for 21 days, impressions (Reprosil ${ }^{\circledR}$ Hydrophilic Vinyl Polysiloxane Impression Material, Dentsply Caulk, Canada) of the samples were made and examined under stereomicroscope under 100× magnification.

\section{Thermal Cycling}

The specimens were subjected to 5000 thermal cycling between 5 and $55^{\circ} \mathrm{C}$ with $15 \mathrm{~s}$ dwell time in each bath and transfer time of 10 seconds between baths for mimicking the mouth conditions. (Thermocycling Test Instrument, Sabri Dental Enterprises Downers Grove, IL, USA).

\section{Preparation of Carious Lesions}

The tooth surfaces for the restorations that were not intended to be subjected to artificial caries procedures were covered with an acid resistant nail varnish. For each of the two groups (UB and B), one of the two restorations 
Flow Chart 1: The study flowchart

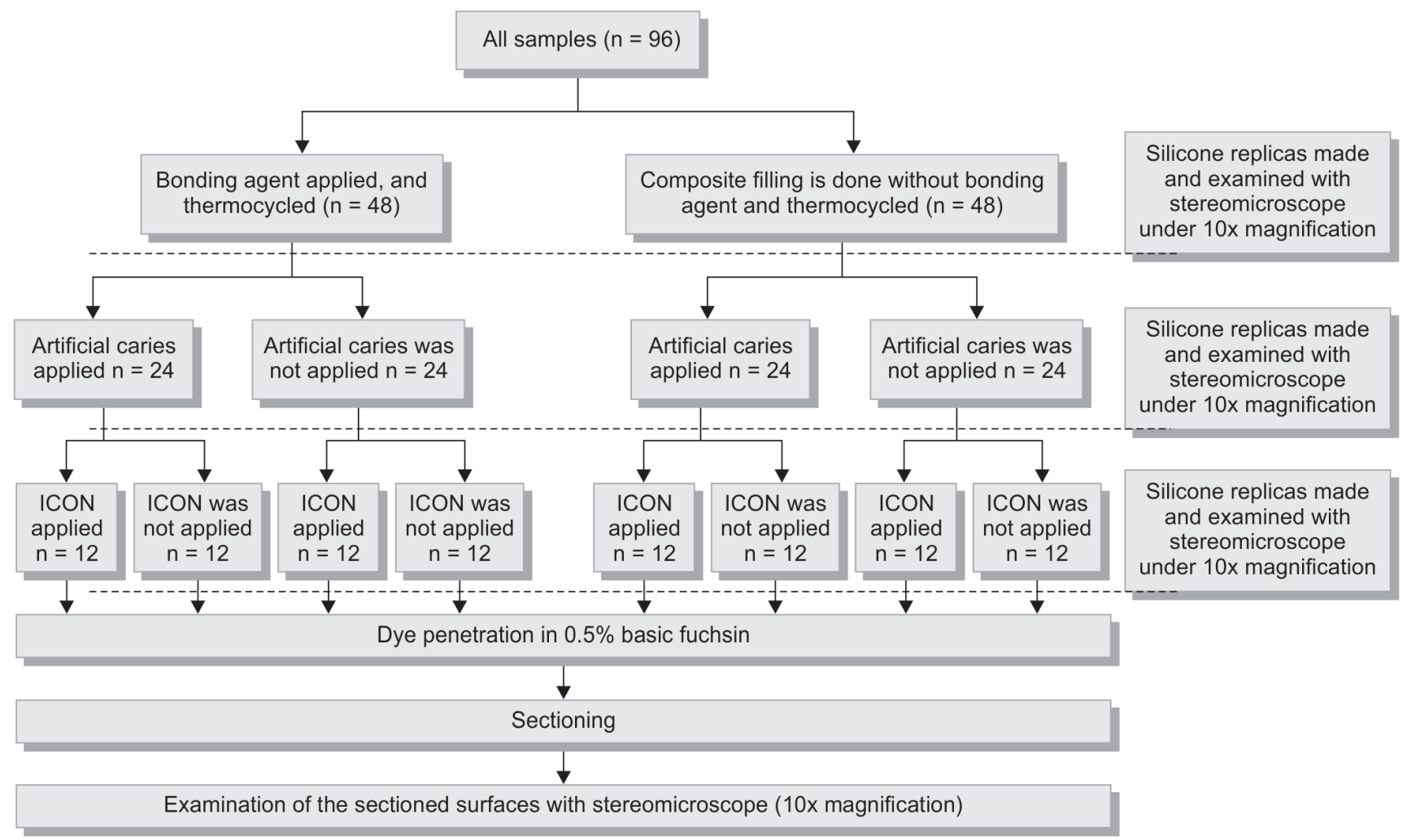

was subjected to noncavitated artificial caries process while the other restorations were left covered with the acid resistant nail polish (Table 1). With the exception of the restorations subjected to the acid demineralization, all other areas of the tooth were protected.

Carious lesions representing the preliminary stage of subsurface enamel demineralization were produced by immersing each sample into $13 \mathrm{ml}$ of $0.1 \mathrm{M}$ lactic acid/ $0.2 \%$ polyacrylic acid (Carbopol C907)/50\% saturated hydroxyapatite solution at $\mathrm{pH} 5.0$ for 72 hours. ${ }^{18}$

Impressions (Reprosil ${ }^{\circledR}$ Hydrophilic Vinyl Polysiloxane Impression Material, Dentsply Caulk, Canada) of the samples were made and examined under stereomicroscope at $100 \times$ magnification.

\section{Application of Resin Infilttrant}

ICON (DMG Hamburg, Germany) was applied to all specimens' with-ICON subgroups according to the manufacturer directions. The cavity margins were etched for 2 minutes using the 15\% hydrochloric acid etching gel. (ICON-Etch etching agent DMG ChemischPharmazeutische Fabrik GmbH, Hamburg, Germany) using the interproximal applicator tips and then rinsed off with water for 30 seconds and air dried. ICON-Dry drying agent (DMG) ethanol was applied to the cavity margins and let set for 30 seconds and air dried again. The ICON resin infiltrant (DMG) was applied to the cavity margins for 3 minutes using the interproximal applicator tips then light cured for 40 seconds (WIP Junior Dental Curing Light, Bisco). A second layer of resin infiltrant was applied over the previous layer for 1 minute and light cured for 40 seconds.

Impressions (Reprosil ${ }^{\circledR}$ Hydrophilic Vinyl Polysiloxane light Body impression material, Dentsply International, USA) of the samples were made and examined under stereomicroscope at $100 \times$ magnification.

Table 1: Distribution of the specimens through the study groups

\begin{tabular}{lll}
\hline & Artificial caries process & ICON \\
\hline Cavity gingival margin left nonbonded $(\mathrm{UB})$ & Artificial caries process (UB-C) & Without ICON (N=12) \\
$(\mathrm{N}=48)$ & $(\mathrm{N}=24)$ & ICON $(\mathrm{N}=12)$ \\
& Left untreated (UB-U) & Without ICON $(\mathrm{N}=12)$ \\
& $(\mathrm{N}=24)$ & ICON $(\mathrm{N}=12)$ \\
Cavity gingival margin conventionally treated with bonding agent $(\mathrm{B})$ & Left untreated $(\mathrm{UB}-\mathrm{U})$ & Without ICON (N=12) \\
$(\mathrm{N}=48)$ & $(\mathrm{N}=24)$ & ICON $(\mathrm{N}=12)$ \\
& Left untreated $(\mathrm{B}-\mathrm{U})$ & Without ICON $(\mathrm{N}=12)$ \\
& $(\mathrm{N}=24)$ & ICON $(\mathrm{N}=12)$ \\
\hline
\end{tabular}




\section{Silicone Replica Technique}

A Vinyl Polysiloxane impression was made of all the specimens: 1- after restorations were made; 2- after thermal cycling; 3 - after artificial caries procedures; and 4after the application of the resin infiltrant. The impression surfaces were examined using a stereomicroscope at 100x magnification and the resin tag lengths were measured using the micrometer incorporated to the microscope (Figs 2A and B). The evaluation of gap formation was performed using the impressions made from the surface margins. Impressions were evaluated from the point of view of the amount of penetration of the impression material through the gaps at the gingival margins of the restorations.

\section{Dye Penetration Procedures}

The apices of all teeth were sealed with the same composite material and the teeth were coated with two layers of nail varnish leaving a $1 \mathrm{~mm}$ window at restoration margins. The specimens were immersed in $0.5 \%$ basic fuchsine dye solution at $37^{\circ} \mathrm{C}$ for 24 hours.

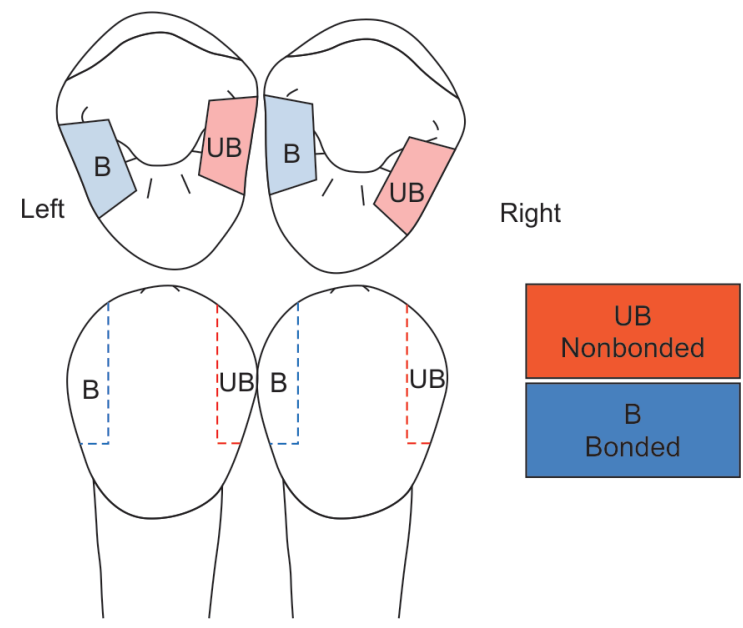

Fig. 1: Cavity preparations and restorations

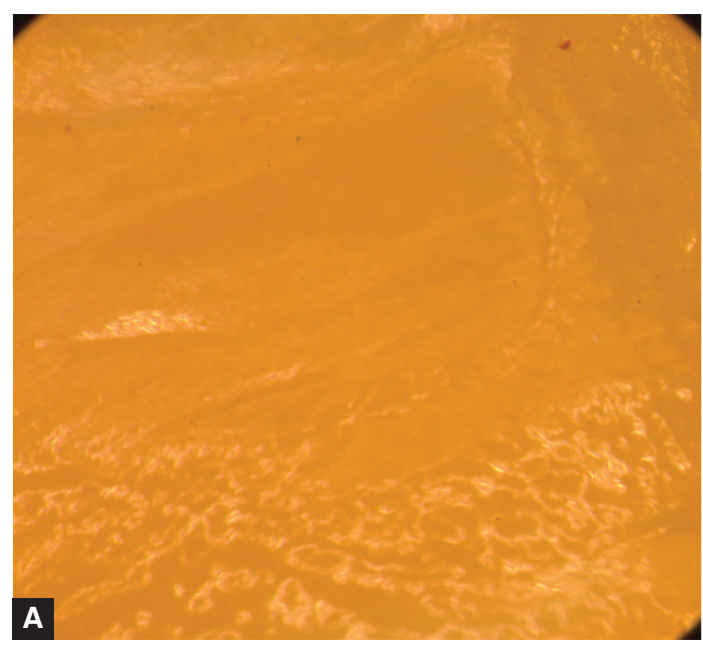

Evaluation of the sectioned surfaces by independent examiners using stereomicroscope.

After die penetration, the test samples were sectioned into three slices longitudinally in mesiodistal direction with an Isomet cutting machine (Buehler IL, USA) and the penetration of the die material was measured with stereomicroscope with $20 \times$ magnification using a subjective visual analog scale with four scales:

$0=$ no penetration of the dye;

$1=$ dye penetration through the half of the gingival floor;

$2=$ dye penetration all the way through the gingival floor;

$3=$ dye penetration through the axial wall of the preparation (Figs 3 and 4).

Each examiner assessed the three sections of each sample independently from the other examiner, and the mean obtained from these three sections for each sample was compared. Cohen's Kappa, calculated to determine inter- and intraexaminer reproducibility was 0.99 and 0.95 , respectively.

\section{Evaluation of Sectioned Surfaces with SEM}

After the evaluation of die penetration, four samples, which showed a microleakage value that was the closest to the mean value for that group, were used for SEM evaluation (Fig. 5).

\section{Statistical Evaluation of the Data}

Statistical analysis was performed using a statistical software package (SPSS, version 15.0, SPSS Inc., Chicago, IL, USA). As the majority of groups did not exhibit normal data distribution (Kolmogorov-Smirnov test), nonparametric tests were used (Kruskall-Wallis test, Mann-Whitney U test, and Wilcoxon Sign Rank test) for pair wise comparisons at the $95 \%$ significance level.

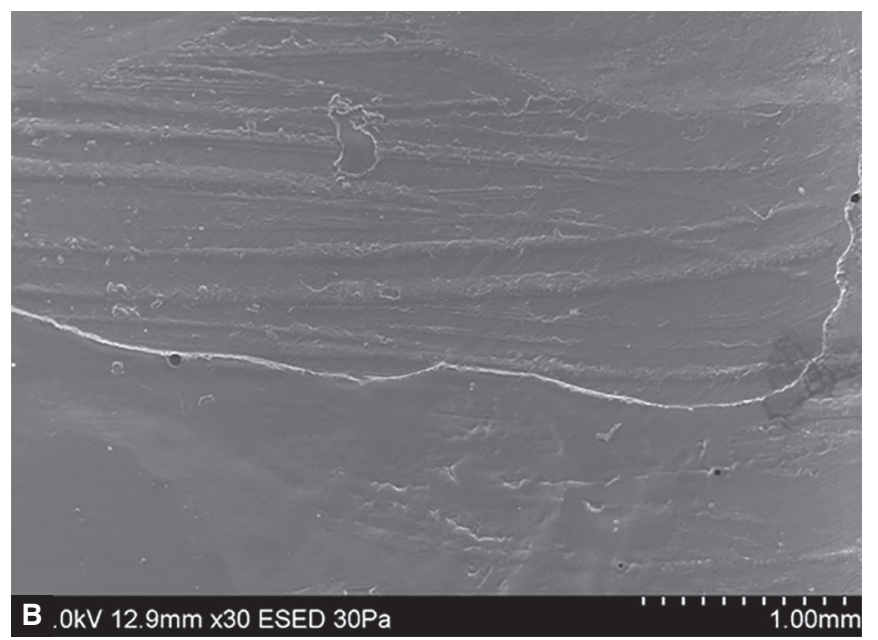

Figs 2A and B: A view of silicone replica with resin tags and its SEM view 


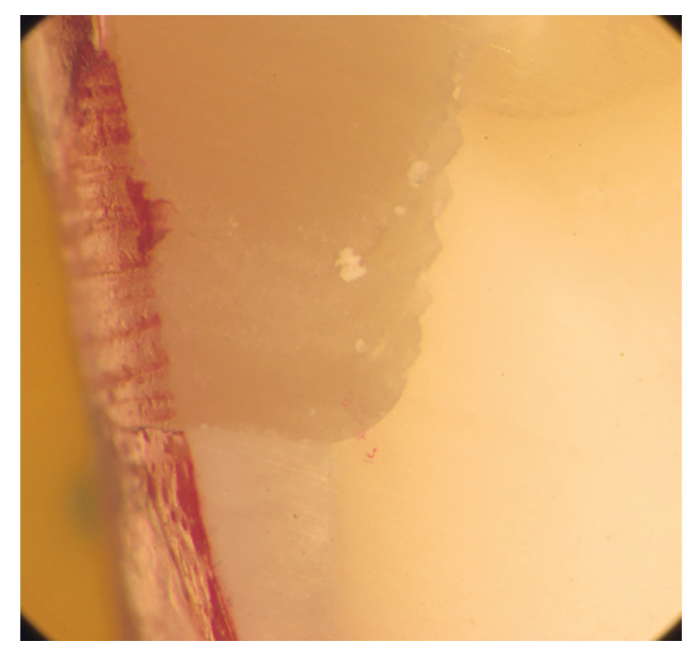

Fig. 3: No dye penetration under the composite

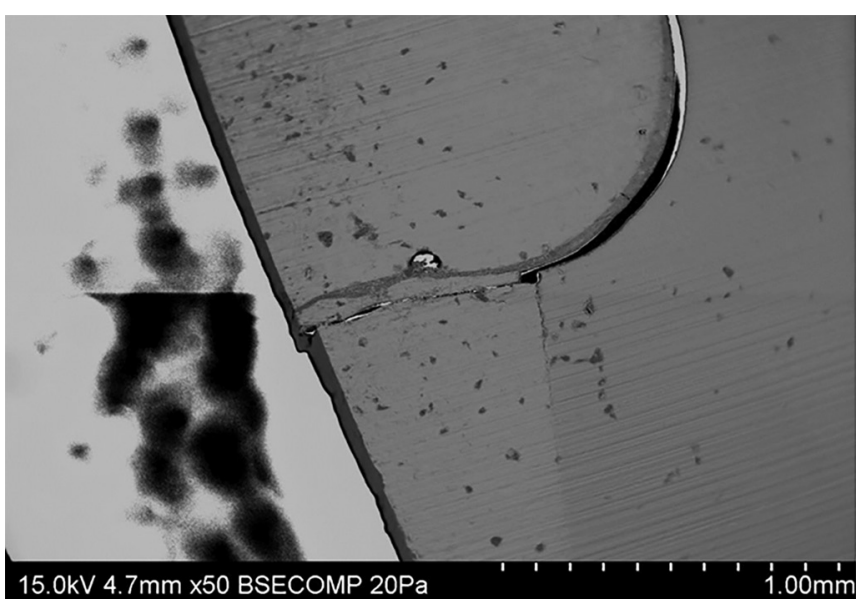

Fig. 5: Bonded, without caries, without ICON

\section{RESULTS}

\section{Marginal Gap Measurements}

The result of silicone tag lengths at the margins of the restorations in different stages of sample preparation is presented in Table 2. UB group sample surfaces showed slightly longer silicone tag lengths than B group surfaces, but the differences were not statistically significant $(\mathrm{p}>0.05)$.

In all groups, thermocycling and artificial caries significantly increased the silicone tag length $(\mathrm{p}<0.05)$ (Table 3).

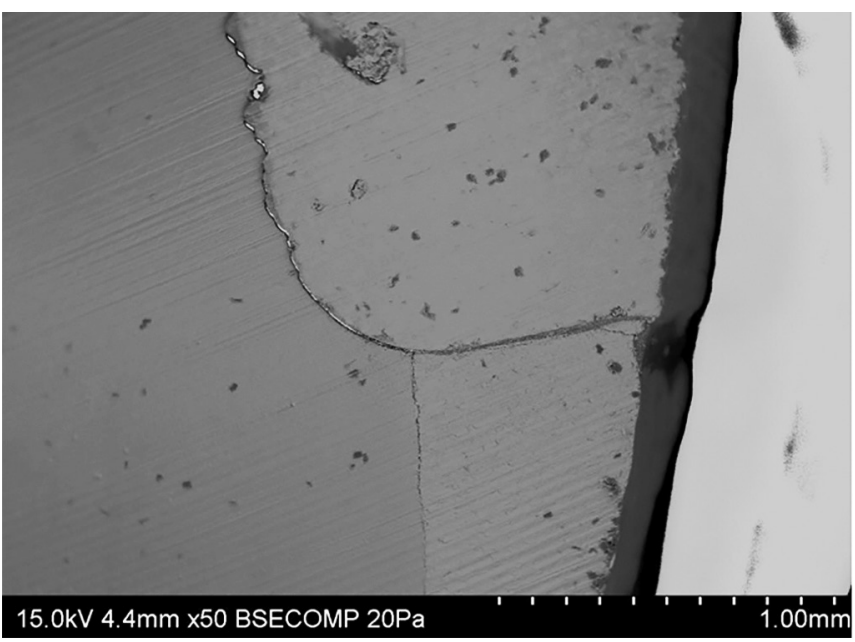

Fig. 4: Bonded, with caries with ICON

For both nonbonded and bonded groups; in the nonartificial caries groups, after ICON application, no silicone tags were detected at the restorationenamel interfaces. In the artificial caries groups, statistically significant $(\mathrm{p}<0.05)$ (Table 3) shorter tag lengths were observed after ICON application. ICON application created gapfree margins and closed the gaps, which were previously presented at the same cavity margins.

\section{Microleakage Evaluations}

Results of the evaluation of the different microleakage groups are presented in Table 4 and statistical differences were presented in Table 5.

\section{Comparison of Microleakage for the Non-bonded Groups}

The statistical evaluation $(\mathrm{p}<0.05)$ revealed that UBCWI (2.41) = UBWI (2.25) > UBI (0.41) = UBCI (0.33).

For nonbonded groups, the highest mean microleakage values were observed in the artificial caries group without ICON application (UBCWI, mean $=2.41$; median =2). Although the mean microleakage value for the nonbonded group with artificial caries without ICON application (UBCWI) was higher than the nonbonded

Table 2: Mean length of silicone tags $(\mu \mathrm{m})$ and standard deviation (SD)

\begin{tabular}{llllll}
\hline Groups & & \multicolumn{3}{c}{ Applications } \\
\cline { 3 - 6 } & & Composite restoration & Thermocycling & Caries application & ICON application \\
\hline Non- & UBI & $0.035 \pm 0.06$ & $0.099 \pm 0.07$ & - & $0.000 \pm 0.00$ \\
bonded & UBCWI & $0.016 \pm 0.32$ & $0.089 \pm 0.10$ & $0.229 \pm 0.28$ & - \\
& UBCI & $0.038 \pm 0.04$ & $0.044 \pm 0.02$ & $0.239 \pm 0.27$ & $0.036 \pm 0.08$ \\
& UBWI & $0.027 \pm 0.04$ & $0.092 \pm 0.06$ & - & - \\
Bonded & $\mathrm{BI}$ & $0.006 \pm 0.02$ & $0.054 \pm 0.01$ & - & $0.000 \pm 0.00$ \\
& $\mathrm{BCWI}$ & $0.026 \pm 0.09$ & $0.048 \pm 0.02$ & $0.095 \pm 0.03$ & - \\
& $\mathrm{BCl}$ & $0.027 \pm 0.01$ & $0.043 \pm 0.02$ & $0.154 \pm 0.23$ & - \\
& $\mathrm{BWI}$ & $0.014 \pm 0.03$ & $0.141 \pm 0.20$ & - & - \\
\hline
\end{tabular}


Table 3: Wilcoxon signed rank test results for comparison of silicone tag length groups $(p<0.05)$

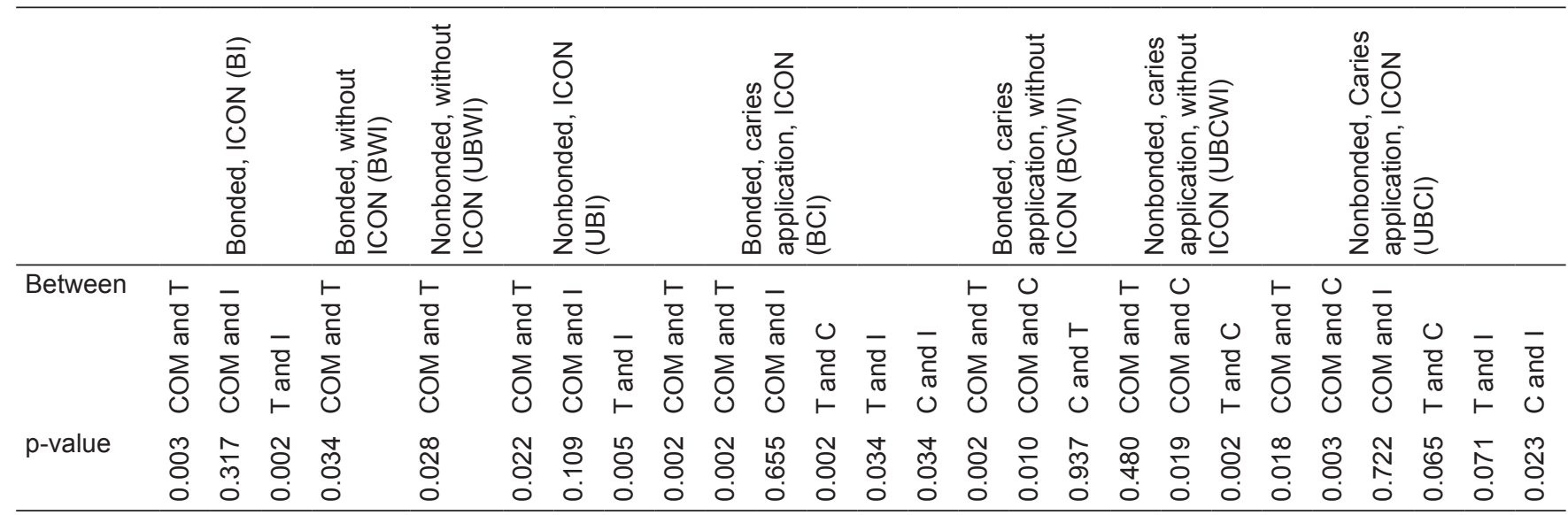

COM: Silicone tag length after composite application; T: Silicone tag length after thermocycling application; C: Silicone tag length after artificial caries application; I: Silicone tag length after ICON application

Table 4: Marginal microleakage

\begin{tabular}{llllll}
\hline Bonding agent application & Artificial caries process & ICON & Mean & SD & Median \\
\hline Cavity gingival margin & Artificial caries & Without ICON UBC & 2.41 & 0.66 & 2 \\
left nonbonded (UB) & Process (-C) & ICON UBCI & 0.33 & 0.49 & 0 \\
& Left untreated (-U) & Without ICON UB & 2.25 & 1.05 & 2 \\
& & ICON UB & 0.41 & 0.51 & 0 \\
Cavity gingival margin & Artificial caries & Without ICON BC & 1.75 & 0.86 & 2 \\
treated with bonding agent (B) & Process (-C) & ICON BCI & 0.25 & 0.45 & 0 \\
& Left untreated (-U) & Without ICON B & 1.66 & 0.65 & 2 \\
& & ICON B & 0.25 & 0.45 & 0 \\
\hline
\end{tabular}

UBCWI: Nonbonded Caries without ICON; UBCI: Nonbonded caries ICON; UBWI: Nonbonded without ICON; UBI: Nonbonded ICON; BCWI: Bonded Caries without ICON; BCI: Bonded Caries ICON; BWI: Bonded without ICON; BI: Bonded ICON; SD: Standard deviation

Table 5: Statistical differences of microleakage scores (Mann-Whitney $U$ tests)

\begin{tabular}{|c|c|c|c|c|c|c|c|}
\hline & $\begin{array}{l}\text { Nonbonded } \\
\text { caries } \\
\text { ICON } \\
(\mathrm{UBCl})\end{array}$ & $\begin{array}{l}\text { Nonbonded } \\
\text { without } \\
\text { ICON } \\
\text { (UBWI) }\end{array}$ & $\begin{array}{l}\text { Nonbonded } \\
\text { ICON } \\
\text { (UBI) }\end{array}$ & $\begin{array}{l}\text { Bonded } \\
\text { Caries } \\
\text { without ICON } \\
(B C W I)\end{array}$ & $\begin{array}{l}\text { Bonded } \\
\text { Caries } \\
\text { ICON } \\
(B C I) \\
\end{array}$ & $\begin{array}{l}\text { Bonded } \\
\text { without } \\
\text { ICON } \\
\text { (BWI) }\end{array}$ & $\begin{array}{l}\text { Bonded } \\
\text { ICON } \\
\text { (BI) }\end{array}$ \\
\hline $\begin{array}{l}\text { Nonbonded Caries without } \\
\text { ICON (UBCWI) }\end{array}$ & 0.000 & 0.755 & 0.000 & 0.068 & 0.000 & 0.020 & 0.000 \\
\hline $\begin{array}{l}\text { Nonbonded Caries ICON } \\
\text { (UBCI) }\end{array}$ & & 0.000 & 0.755 & 0.000 & 0.755 & 0.000 & 0.750 \\
\hline $\begin{array}{l}\text { Nonbonded without ICON } \\
\text { (UBWI) }\end{array}$ & & & 0.000 & 0.291 & 0.000 & 0.178 & 0.000 \\
\hline $\begin{array}{l}\text { Nonbonded ICON } \\
\text { ( UBI) }\end{array}$ & & & & 0.001 & 0.514 & 0.000 & 0.514 \\
\hline $\begin{array}{l}\text { Bonded Caries without ICON } \\
(\mathrm{BCWI})\end{array}$ & & & & & 0.000 & 0.713 & 0.000 \\
\hline $\begin{array}{l}\text { Bonded Caries ICON } \\
(\mathrm{BCl})\end{array}$ & & & & & & 0.000 & 1.00 \\
\hline $\begin{array}{l}\text { Bonded without ICON } \\
\text { (BWI) }\end{array}$ & & & & & & & 0.000 \\
\hline
\end{tabular}

without artificial caries and without ICON group (UBWI, mean $=2.25$; median $=2$ ) the difference was not statistically significant $(\mathrm{p}=0.755)$ as their median microleakage values were the same (Tables 4 and 5).

For all nonbonded groups, although the presence of artificial caries did not cause a statistically meaningful difference (UBCWI and UBWI $\mathrm{p}=0.775$ : UBCI and UBI $\mathrm{p}=0.775)$, the application of ICON caused a statistically significant decrease in microleakage values (UBCI and UBCWI $\mathrm{p}=0.000$; UBI and UBWI $\mathrm{p}=0.000$ ).

\section{Comparison of the Microleakage for the Bonded Groups}

The statistical evaluation revealed that BCWI (1.75) = BWI (1.66) > BCI $(0.25)=\mathrm{BI}(0.25)$.

The highest microleakage values were observed in the group with artificial caries and without ICON (BCWI, 
mean $=1.75 ;$ median $=2$ ) but the difference between the bonded without artificial caries and without ICON group (BWI, mean =1.66; median $=2$ ) was not statistically significant $(\mathrm{p}=0.713)$.

The mean values of bonded group with artificial caries with ICON application $(\mathrm{BCI}$, mean $=0.25$; median $=0$ ) and the mean value of bonded without artificial caries with ICON application (BI, mean $=0.25$; median $=0$ ) were not statistically significant $(\mathrm{p}=1.00)$.

In all bonded sample groups, the presence of artificial caries did not cause a significant difference (BCWI and BWI $p=0.775$ : BCI and BI $p=1.0)$, but the application of ICON resulted in a statistically significant decrease in microleakage values (BCI and BCWI $\mathrm{p}=0.000$; $\mathrm{BI}$ and BWI $\mathrm{p}=0.000)$.

\section{Comparison of Bonded and Nonbonded Groups}

The statistical evaluation revealed that UBCWI (2.41) = UBWI (2.25) > BCWI (1.75) = BWI (1.66) > UBI (0.41) = UBCI $(0.33)=\mathrm{BCI}(0.25)=\mathrm{BI}(0.25)$. Although the mean microleakage values for the bonded groups were lower than the nonbonded groups, the differences were not statistically significant (UBCWI and BCWI $\mathrm{p}=0.068$; UBCI and BCI $\mathrm{p}=0.755$; UBWI and BWI $\mathrm{p}=0.178$; UBI and BI $\mathrm{p}=0.514$. For bonded and nonbonded groups, although artificial caries presence did not make a statistically meaningful difference among them, the presence of infiltrant produced a significant decrease of microleakage in all groups (UBCWI and UBCI $\mathrm{p}=0.000$; UBWI and UBI $\mathrm{p}$ $=0.000 ; \mathrm{BCWI}$ and BCI $\mathrm{p}=0.000$; BWI and BI $\mathrm{p}=0.000$ ).

\section{DISCUSSION}

Many studies show that secondary caries and marginal integrity loss are still accepted as important problems related to composite resin restorations. ${ }^{19-21}$ Demarco et al ${ }^{19}$ published a review which evaluated thirty-four selected clinical trials between 1996 and 2011, investigating posterior composite restorations over periods of at least 5 years of follow-up. They reported that $90 \%$ of the clinical studies indicated that annual failure rates between 1 and 3\% can be achieved with class I and II posterior composite restorations depending on several factors such as tooth type and location, operator, and socioeconomic, demographic and behavioral elements.

Previously, more than ten long-term clinical studies were reviewed by Rezwani-Kaminsky et $\mathrm{al}^{20}$ and they stated that posterior composite restorations may survive successfully for as long as twenty or more years despite of poor material parameters. They reported that long-term performing macrofilled posterior resin based composites exhibited marginal imperfection in class I and II cavities and this micro morphologic deterioration and clinical gap formation do not necessarily lead to secondary caries, and the authors discussed several articles stating the secondary caries as being responsible of 23 to $30 \%$ of the causes of failure of class II restorations.

Kopperud et $\mathrm{al}^{21}$ performed a study on a wider sample population of class II restorations $(n=4,030)$, consisting of resin composites (81.5\%), compomers $(12.7 \%)$, amalgams (4.6\%), and glass-ionomer cement restorations (1.2\%) that were placed in 1,873 patients with a median age of 15 years. In total, $92.7 \%$ of restorations were placed due to primary caries and 5.8\% were replacements. After an average follow-up period of 4.6 years, $61.6 \%$ of the restorations were successful, $11.2 \%$ had failed, and $27.2 \%$ were not available for evaluation. The mean annual failure rate was $2.9 \%$ for resin-composite restorations and secondary caries was the most common reason for replacement (73.9\%), followed by loss $(8.0 \%)$, fracture (5.3\%) and marginal defects (2.4\%).

Alternative treatments to replacement of defective restorations, such as marginal sealing refurbishment and repair, have demonstrated improvement of their clinical properties with minimal intervention. ${ }^{22}$ In a 5-year randomized clinical trial, ${ }^{23}$ amalgam and resin-based composite restorations with localized marginal defects were treated with pit and fissure sealants. This study demonstrated that marginal sealing of restorations is a minimally invasive treatment that may be used instead of the replacement of restorations with localized marginal defects. So, sealing and repair are viable alternatives to replacement, and it can increase significantly the survival of restorations.

Within the limitation of our knowledge, this is the first study to evaluate the effect of a resin infiltrant application on the composite resin restoration margins with artificial caries for microleakage and gap formation. In this study, in all groups, thermocycling and artificial caries significantly increased the silicone tag length and microleakage. Application of an infiltrant over composite restorations significantly decreased the gap formation and microleakage at the cavity margin whether a bonding agent was used or not and it has efficiently reduced the microleakage even if there is caries at the composite-enamel interface.

After completed all of the restorations to mimic the oral environment thermocycling was done. Thermal cycling causes interface degradation and increase microleakage ${ }^{14}$ As the process is performed in a water bath, their water absorption and ingredient release behaviors are also in action. ${ }^{24}$ In this study when the tag lengths before and after thermocycling were compared, significantly longer tag lengths were observed after thermocycling, showing that thermocycling significantly affects the dimensions of gaps on the composite-enamel interface. 
In this presented study, the composite restorations were made in two increments with $2 \mathrm{~mm}$ thicknesses to restore the proximal box cavity with $3 \mathrm{~mm}$ of height and only one type of composite, bonding system, restorative technique and curing light were used to avoid the influence of composition of the restorative material and technique. A conventional multi-step adhesive, Optibond FL, was used providing clinically successful adhesion to enamel and dentin. Although, the application of dental adhesives were accepted as a fundamental step for resin restorations, still many studies have displayed varying levels of microleakage associated with the use etch and rinse and self-etch adhesives in permanent teeth. ${ }^{25}$

In this study, evaluation of the gap formation results: the presence of an adhesive resin diminished the gap formation as the nonbonded surfaces showed slightly greater silicone tag lengths than bonded surfaces, however the differences were not statistically significant $(p>0.05)$. According to these results, dentin-bonding application does not help significantly reduce the gap formation and microleakage of class II restorations in permanent teeth. Souza-Junior et $\mathrm{al}^{26}$ stated that the presence of gaps is considered the first sign of restoration failure, clinically evidenced by marginal staining. It has been accepted that a detectable marginal gap would lead to interfacial leakage.

Impressions were evaluated from the point of view of the amount of penetration of the impression material through the gaps at the gingival margins of the restorations. For both bonded and nonbonded groups, in the nonartificial caries groups, after ICON application, no silicone tags were detected at the restoration-enamel interfaces. In the artificial caries groups, very short tag lengths were observed after ICON application. These results show that resin infiltrants can penetrate into the gaps even if bonding application still exist there, formed between the restoration-enamel interfaces by capillary or canalicular action and closed the gaps, which were previously present at the same cavity margins. According to these results infiltrant can also eliminate the gap formation if there is no caries at the compositeenamel interface and significantly reduce the gaps in the presence of artificial caries at the restoration-enamel margin.

The most common method of assessing the sealing efficiency of a restorative material is microleakage evaluation. ${ }^{24}$ Evaluation of the microleakage results of this study; although the microleakage values were higher among the all study groups in which composite restorations were completed without use of a bonding agent the difference was not statistically significant between bonded and nonbonded groups.
For nonbonded groups, unexpectedly lesser micro leakage values were observed with artificial caries and ICON application group (0.33) compared to without artificial caries and ICON application group (0.41) but the difference was not statistically significant. This may be due to deeper penetration of the infiltrant to the area. The possible explanation may be the effectiveness of the acid application to the caries areas. The acid for using infiltrant application is hydrochloric acid gel (icon-etch). It is applied for 120 seconds using the foil applicator and this prolong application time of strong acid may be became more effective on the decalcified tissue and to increase the penetration of infiltrant on the artificial caries area than sound area.

For all bonded and nonbonded study groups, although the presence of artificial caries did not cause a statistically meaningful difference, the application of infiltrant caused a statistically significant decrease in microleakage values.

Adhesive dentistry tries to obtain capillary forces and marginal sealing by the application of adhesive systems and resin composites. ${ }^{17,27}$ Penetration depths of the adhesive were significantly lower compared with those of the infiltrant. It can be concluded that infiltrant resins with higher penetration capacity show superior ability to penetrate natural lesions compared with resins with lower penetration capacity. ${ }^{27}$ According to our study results, a similar or better effect observed from infiltrant on the marginal defects and initial caries developing at the resin restorations and enamel margins.

In this study, the infiltrant is shown to be effective when applied after the thermocycling or in presence of a carious lesion at the margin of a previously restoration. Like surface sealants, nanotechnology liquid polishers or other covering agents, resin infiltrant can increase class II resin composite restorations effectiveness also reduce the risk of the need for a more complex restorative therapy, which may cause sound tooth tissue lost, as well as stress on the dental pulp. Further, studies on evaluation of the long-term results and the effectiveness of periodical application of resin infiltrant on reducing marginal leakage are needed.

\section{CONCLUSION}

Within the limits of this study the following conclusions can be made:

Thermocycling and caries presence cause interface degradation, gap occurrence and increased microleakage. A resin infiltrant can reduce these effects and decrease microleakage in class II restorations. For these types of restorations with resin infiltrant application, replacement and repair therapies can became unnecessary. 
The null hypothesis tested $\left(\mathrm{H}_{0}\right.$ : Bonding application helps to reduce the gap formation and microleakage and the resin infiltrant could not eliminate the microleakage and gap at the composite resin enamel margin neither with nor without artificial caries lesions in enamel) was defeated.

\section{Clinical Significances}

The application of resin infiltrant can repair the gaps or stop the initial caries formation on the marginal surfaces, so, that it may increase the survival of class II resin restorations on the mouth.

\section{REFERENCES}

1. Ekstrand K, Martignon S, Bakhshandeh A, Ricketts DN. The nonoperative resin treatment of proximal caries lesions. Dental Update 2012;39:614-622.

2. Martignon S, Ekstrand KR, Gomez J, Lara JS, Cortes A. Infiltrating/sealing proximal caries lesions: A 3-year randomized clinical trial. J Dent Res 2012;91:288-292.

3. Bakhshandeh A, Qvist V, Ekstrand KR. Sealing occlusal lesions in adults referred for restorative treatment: 2-3 years of follow-up. Clin Oral Invest 2012;16:521-529.

4. Ekstrand KR, Bakhshandeh A, Martignon S. Treatment of proximal superficial caries lesions on primary molar teeth with resin infiltration and fluoride varnish versus fluoride varnish only: Efficacy after 1 year. Caries Res 2010;44:41-46.

5. Vidnes-Kopperud S, Tveit AB, Espelid I. Changes in the treatment concept for approximal caries from 1983 to 2009 in Norway. Caries Res 2011;45:113-120.

6. Pitts NB, Wefel JS. Remineralization/desensitization: what is known? What is the future? Adv Dent Res 2009;21:83-86.

7. Meyer-Lueckel H, Paris S. Progression of artificial enamel caries lesions after infiltration with experimental light curing resins. Caries Res 2008;42:117-124.

8. Schmidlin PR, Seemann R, Filli T, Attin T, Imfeld T. Sealing of minimally invasive class II fillings (slot) using an adhesive patch: Sealant margin extension for prevention. Oper Dent 2007;32:482-487.

9. BeauchampJ, Caufield PW, Crall JJ, Donly KJ, Feigal R, Gooch E, Ismail A, Kohn W, Siegal M, Simonsen R. Evidence-based clinical recommendations for the use of pit-and-fissure sealants: a report of the American Dental Association Council on Scientific Affairs. Dent Clin North Am 2009;53:131-147.

10. Kantovitz KR, Pascon FM, Nobre-dos-Santos M, PuppinRontani RM. Review of the effects of infiltrants and sealers on noncavitated enamel lesions. Oral Health Preventive Dentistry 2010;8:295-305.

11. Owens BM, Johnson WW. Effect of new generation surface sealants on the marginal permeability of class $\mathrm{V}$ resin composite restorations. Oper Dent 2006;31:481-488.
12. Atabek D, Sillelioglu H, Olmez A. The efficiency of a new polishing material: Nanotechnology liquid polish. Oper Dent 2010;35:362-369.

13. Dos Santos PH, Pavan S, Anissuncao WG, Consani S, CorrerSobrinho L, Sinhoreti MA. Influence of surface sealants on microleakage of composite resin restorations. J Dent Child 2008;75:204-208.

14. Lima AF, Soares GP, Vasconcellos PH, Ambrosano GM, Marchi GM, Lovadino JR, Aguiar FH. Effect of surface sealants on microleakage of class II restorations after thermocycling and long-term water storage. J Adhes Dent 2011;13: 249-254.

15. Silva Santana SV, Bombana AC, Florio FV, Basting RT. Effect of surface sealants on marginal microleakage in class $\mathrm{V}$ resin composite restorations. J Est Restor Dent 2009;21:397-406.

16. Ramos RP, Dibb RG, Mondelli J. Effect of three surface sealants on marginal sealing of class $\mathrm{V}$ composite resin restorations. Oper Dent 2000;25(5):448-445.

17. Antonson SA, Yazici AR, Okte Z, Villalta P, Antonson DE, Hardigan PC. Effect of resealing on microleakage of resin composite restorations in relationship to margin design and composite type. Eur J Dent 2012;6:389-395.

18. White DJ. Use of synthetic polymer gels for artificial carious lesions preparation. Caries Res 1987;21:228-242.

19. Demarco FF, Correa MB, Cenci MS, Moraes RR, Opdam NJ. Longevity of posterior composite restorations: not only a matter of materials. Dent Mater 2012;28:87-101.

20. Rezwani-Kaminsky T, Kamann W, Gaengler P. Seconder caries susceptibility of teeth with long-term performing composite restoration. J Oral Rehab 2002;29:1131-1138.

21. Kopperud SE, Tveit AB, Gaardan T, Sandvik L, Espelid I. Longevity of posterior dental restorations and reason of failure. Eur J Oral Sci 2012;120:539-548.

22. Fernandez EM, Martin JA, Angel PA, Mjor IA, Gordan VV. Moncada GA. Survival rate of sealed, refurbished and repaired defective restorations: 4-year follow-up. Braz Dent J 2011;22:134-139.

23. MartinJ1,FernandezE,EstayJ, Gordan VV,MjorIA,MoncadaG. Minimal invasive treatment for defective restorations: 5-year results using sealants. Oper Dent 2013;38:125-133.

24. Cenci MS, Pereira-Cenci T, Donassollo TA, Sommer L, Strapasson A, Demarco FF. Influence of thermal stress on marginal integrity of restorative materials. J Appl Oral Sci 2008;16:106-110.

25. Gungor HC, Canoglu E, Cehreli ZC. The effects of dentin adhesives and liner materials on the microleakage of class II resin composite restorations in primary and permanent teeth.

26. Souza-Junior E, Souza-Regis M, Alonso RC, Freitas A, Sinhoreti M, Cunha L. Effect of the curing method and composite volume on marginal and internal adaptation of composite restoratives. Oper Dent 2011;36:231-238.

27. Paris S, Meyer-Lueckel H. Infiltrants inhibit progression of natural lesions in vitro. J Dental Res 2010;89:1276-1280. 